\title{
Endoscopic placement of a covered self-expandable metal stent in the minor papilla in patients with chronic pancreatitis and pancreas divisum
}

Pancreas divisum is the most common anatomic variant of pancreatic development and may lead to chronic pancreatitis $[1,2]$. Endoscopic stenting of the dorsal pancreatic duct is a safe and effective treatment for patients with chronic pancreatitis and pancreas divisum $[3,4]$. Here we report three cases of chronic pancreatitis and pancreas divisum successfully treated with endoscopic placement of a self-expanding metal stent (SEMS) in the minor papilla.

Between June 2005 and July 2006, three patients with chronic pancreatitis and pancreas divisum received a SEMS for relief of abdominal pain that was persisting despite several attempts at pancreatic plastic stent implantation (Wilson-Cook Medical GI Endoscopy, Winston-Salen, NC, USA). All patients received a covered pancreatic-type SEMS (Taewoong Medical Co., Seoul, South Korea), which was implanted into the minor papilla and the dorsal pancreatic duct using a standard technique with a duodenoscope (TJF-140 or TJF-160, Olympus Corp., Japan). All three endoscopic SEMS placements were successful and there were no complications relating to endoscopic retrograde cholangiopancreatography (ERCP). Interestingly, 6 months after implantation, both a plain abdominal radiograph and duodenoscopy showed that all three SEMS had passed spontaneously ( Fig. 1).
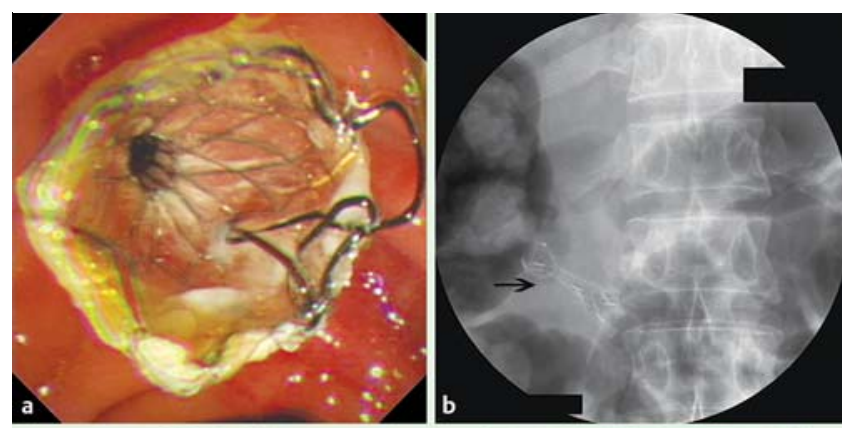

Fig. 1 Endoscopic placement of a covered self-expandable metal stent (SEMS) in a patient with chronic pancreatitis and pancreas divisum. a Endoscopic view of the SEMS in the minor papilla. b A waist is visible in the stent. c The stricture in the minor papilla has been dilated successfully with disappearance of the stent waist 2 weeks after SEMS implantation. d Endoscopic view of the minor papilla 6 months after SEMS implantation. The orifice of the minor papilla has enlarged significantly.

ERCP showed no new stones in the dorsal pancreatic duct and no further intervention was carried out. At a mean followup of 27 months (rang 25-30 months), all patients were free of pain and none had steatorrhea or diabetes mellitus (- Table 1).

The results of our pilot trial with three patients suggests that covered SEMS should be considered as an alternative to the en- doscopic management of chronic pancreatitis and pancreas divisum. Moreover, as all SEMS passed spontaneously through the minor papilla and dorsal pancreatic duct, further endoscopic extraction was not required.

Endoscopy_UCTN_Code_TTT_1AR_2AZ Endoscopy_UCTN_Code_TTT_1AR_2AI

Table 1 Patient and stent data and pain scores.

\begin{tabular}{|c|c|c|c|c|c|c|c|}
\hline \multirow[t]{2}{*}{ Patient } & \multirow[t]{2}{*}{ Age/sex } & \multirow{2}{*}{$\begin{array}{l}\text { No. of sessions } \\
\text { of PS placement }\end{array}$} & \multirow{2}{*}{$\begin{array}{l}\text { SEMS } \\
\text { (diameter, length) }\end{array}$} & \multicolumn{3}{|c|}{ Pain score (VAS) } & \multirow{2}{*}{$\begin{array}{l}\text { Follow-up } \\
\text { (month) }\end{array}$} \\
\hline & & & & Pre-PS & Post-PS & After SEMS & \\
\hline 1 & $58 / \mathrm{M}$ & $3(7 \mathrm{~F}, 8.5 \mathrm{~F}, 10 \mathrm{~F})$ & $8 \mathrm{~mm}, 30 \mathrm{~mm}$ & 8 & 7 & 0 & 30 \\
\hline 2 & $47 / M$ & $2(7 \mathrm{~F}, 8.5 \mathrm{~F})$ & $8 \mathrm{~mm}, 30 \mathrm{~mm}$ & 7 & 6 & 0 & 26 \\
\hline 3 & $43 / \mathrm{M}$ & $3(7 \mathrm{~F}, 8.5 \mathrm{~F}, 10 \mathrm{~F})$ & $8 \mathrm{~mm}, 30 \mathrm{~mm}$ & 6 & 4 & 0 & 25 \\
\hline
\end{tabular}

PS, plastic stent; F, French; SEMS, self-expandable metal stent; VAS, visual analog scale $(0=$ no pain; $10=[$ imaginary $]$ maximum pain). 
Z. Liao, Z. S. Li, W. Wang, Z. Ye, X. W. Lai, X. T. Wang, D. W. Zou Chronic Pancreatitis Study Group, Department of Gastroenterology, Digestive Endoscopy Center, Changhai Hospital, Second Military Medical University, China

\section{References}

1 Klein SD, Affronti JP. Pancreas divisum, an evidence-based review: part I, pathophysiology. Gastrointest Endosc 2004; 60: 419 425

2 Klein SD, Affronti JP. Pancreas divisum, an evidence-based review: part II, patient selection and treatment. Gastrointest Endosc 2004; 60: 585-589

3 Vitale GC, Vitale M, Vitale DS et al. Long-term follow-up of endoscopic stenting in patients with chronic pancreatitis secondary to pancreas divisum. Surg Endosc 2007; 21: $2199-2202$

4 Liao Z, Gao R, Wang W et al. A systematic review on endoscopic detection rate, endotherapy, and surgery for pancreas divisum. Endoscopy 2009; 41: 439-444
Bibliography

DOI $10.1055 / \mathrm{s}-0029-1214851$

Endoscopy 2009; 41: E302-E303

(c) Georg Thieme Verlag KG Stuttgart · New York . ISSN 0013-726X

\section{Corresponding author}

\section{Professor Z. S. Li}

Department of Gastroenterology

Digestive Endoscopy Center

Changhai Hospital

Second Military Medical University 168 Changhai Road

Shanghai 200433

China

Fax: +86-21-55621735

zhaoshenli@hotmail.com 